\title{
Vaccine Responses in Patients with Rheumatoid Arthritis Treated with Certolizumab Pegol: Results from a Single-blind Randomized Phase IV Trial
}

\author{
Alan J. Kivitz, Joy Schechtman, Michele Texter, Andreas Fichtner, Marc de Longueville, \\ and Elliot K. Chartash
}

ABSTRACT. Objective. To evaluate the humoral immune response to pneumococcal and influenza vaccination in adults with rheumatoid arthritis (RA) receiving certolizumab pegol (CZP).

Methods. In this 6-week, single-blind, placebo-controlled trial with optional 6-month open-label extension (NCT00993668), patients were stratified by concomitant methotrexate (MTX) use and randomized to receive CZP $400 \mathrm{mg}$ (loading dose; according to CZP label) or placebo at weeks 0, 2, and 4. Pneumococcal (polysaccharide 23) and influenza vaccines were administered at Week 2. Satisfactory humoral immune response, defined as $\geq 2$-fold titer increase in $\geq 3$ of 6 pneumococcal antigens and $\geq 4$-fold titer increase in $\geq 2$ of 3 influenza antigens, were assessed independently 4 weeks after vaccination.

Results. Following pneumococcal vaccination, $62.5 \%$ of placebo patients and $54.5 \%$ of CZP patients without effective titers at baseline achieved a humoral response (difference in proportions was -8.0 percentage points; $95 \%$ CI -22.5 to $6.6 \%$ ). Following influenza vaccination, $61.4 \%$ of placebo and $53.5 \%$ of CZP patients without effective titers at baseline achieved a humoral response (difference in proportions: -8.0 percentage points; $95 \% \mathrm{CI}-22.9$ to $7.0 \%$ ). In all patients, including those with effective titers at baseline, $58.2 \%$ of placebo and $53.3 \%$ of CZP patients developed satisfactory pneumococcal titers, and $54.1 \%$ of placebo and $50.5 \%$ of CZP patients developed satisfactory influenza antibody titers. Vaccine responses to pneumococcal and influenza antigens were reduced similarly in both treatment groups with concomitant MTX use.

Conclusion. Humoral immune responses to pneumococcal and influenza vaccination are not impaired when given during the loading phase of CZP treatment in patients with RA. (ClinicalTrials.gov NCT00993668). (First Release March 1 2014; J Rheumatol 2014;41:648-57; doi:10.3899/jrheum.130945)

Key Indexing Terms:

RHEUMATOID ARTHRITIS PNEUMOCOCCAL VACCINE INFLUENZA VACCINE HUMORAL IMMUNE RESPONSE

CERTOLIZUMAB PEGOL

TUMOR NECROSIS FACTOR INHIBITOR

It has been well documented that patients with rheumatoid arthritis (RA) are more susceptible to infection than similar

From the Altoona Center for Clinical Research, Duncansville, PA; Sun Valley Arthritis Center, Peoria, AZ; UCB Pharma, Smyrna, GA, USA; UCB Pharma, Monheim, Germany; UCB Pharma, Brussels, Belgium.

Funded by UCB Pharma. AJK has received research support from Abbott, Amgen, BMS, Celgene, Janssen, Merck, Novartis, Pfizer, and UCB Pharma; and consulting fees from Abbott, BMS, Celgene, Janssen, Pfizer, and UCB Pharma; JS has received consulting fees and speakers' bureau fees from UCB Pharma; MT was previously an employee of UCB Pharma; $A F$ and MdL are current employees of UCB Pharma; EKC was previously an employee of UCB Pharma and holds UCB Pharma stock/stock options/bond holdings.

A.J. Kivitz, MD, Altoona Center for Clinical Research; J. Schechtman, $M D$, Sun Valley Arthritis Center; M. Texter, PhD, UCB Pharma, Smyrna, Georgia; A. Fichtner, PhD, UCB Pharma, Monheim, Germany; M. de Longueville, MD, UCB Pharma, Brussels, Belgium; E.K. Chartash, MD, PhD, UCB Pharma, Smyrna, Georgia.

Address correspondence to Dr. A.J. Kivitz, Altoona Center for Clinical Research,Duncansville,PA 16635,USA.E-mail: ajkivitz@yahoo.com Full Release Article. For details see Reprints/Permissions at jrheum.org Accepted for publication December 19, 2013. populations without RA. This increased risk of infection may be due to underlying immune system dysfunction, because historical reports prior to the availability of immunosuppressive treatments and recent studies adjusted for corticosteroid use have demonstrated an increase in infection rates in patients with RA, especially in those with active disease ${ }^{1,2}$. The use of immunosuppressive agents for RA treatment may contribute to this increased risk ${ }^{3,4,5,6}$. The recent development of tumor necrosis factor (TNF) inhibitors has also raised concerns regarding increased infection risks in patients treated with these drugs ${ }^{3,6}$. Given these concerns, treatment guidelines recommend routine use of pneumococcal and inactivated influenza vaccines for immune-compromised patients, including those who are receiving TNF inhibitors ${ }^{7,8}$. Use of live vaccines is not recommended in patients receiving TNF inhibitors because there are currently insufficient safety data ${ }^{7,8}$, a situation reflected in the prescribing information ${ }^{9,10,11,12,13}$. Despite recommendations, vaccination coverage rates (including

Personal non-commercial use only. The Journal of Rheumatology Copyright $\odot$ 2014. All rights reserved. 
non-live vaccines such as the inactivated influenza and pneumococcal vaccines) are lower in patients with RA compared to the general population ${ }^{14,15}$, partly owing to concerns about vaccination safety and efficacy in patients treated with immunomodulatory therapies ${ }^{16}$.

Response to vaccination varies among patients with RA who are receiving TNF inhibitor therapy, both with and without concomitant corticosteroids and/or nonbiologic disease-modifying antirheumatic drugs (DMARD). A prospective study showed that patients receiving TNF inhibitors with methotrexate (MTX) had a lower response to the influenza vaccine than those receiving TNF inhibitors alone $^{17}$. In addition, the response to influenza vaccination is lower in RA patients with preexisting protective antibody titers receiving $\mathrm{TNF}$ inhibitor treatment ${ }^{18}$. Immune responses to the 23 valent pneumococcal polysaccharide vaccine are also variable in patients receiving TNF inhibitor therapy with and without DMARD ${ }^{18,19,20,21}$. While protective titers have been shown in both TNF inhibitor and control groups, responses to vaccination ( $\geq 2$-fold increases in titer from baseline) have been lower, or no different from controls, in those receiving TNF inhibitors ${ }^{18,19,21}$. Variable vaccine response has also been reported for other biologic agents that inhibit $\mathrm{T}$ cell co-stimulation or deplete $\mathrm{B}$ cells $^{22,23,24}$; vaccine response can also be affected by other co-factors such as age, sex, and genomics ${ }^{25}$.

Certolizumab pegol (CZP), a univalent Fc-free PEGylated anti-TNF agent, has previously demonstrated efficacy in reducing signs and symptoms, and inhibiting progression of structural joint damage, in patients with moderate to severely active RA when used either in combination with MTX or as monotherapy ${ }^{26,27,28}$. CZP has also demonstrated efficacy in Crohn disease, axial spondyloarthritis, psoriatic arthritis, and psoriasis $29,30,31,32,33,34,35$. However, the effect of CZP treatment on antibody responses to pneumococcal and influenza vaccination in patients with RA has not been evaluated. In our study we assessed the humoral immune responses to the pneumococcal vaccine (purified capsular polysaccharides from Streptococcus pneumonia) and the trivalent influenza virus vaccine (inactivated influenza virus) in adult patients with RA receiving either CZP or placebo, with or without existing nonbiologic therapy. The hypothesis was that there would be no difference in immune response between placebo-treated and CZP-treated patients.

\section{MATERIALS AND METHODS}

Study design. This 6-week, post-approval commitment, randomized, single-blind (patient), placebo-controlled trial, with an optional 6-month open-label extension (OLE) phase in which all patients received CZP (Figure 1A), was conducted between September 2009 and February 2011 at 43 US centers. The study complied with the principles of the Declaration of Helsinki and was approved by institutional review boards at each participating center. All patients provided written informed consent. Our study was registered with ClinicalTrials.gov (NCT00993668).

Eligible patients were stratified by concomitant MTX use and randomized 1:1 to receive either CZP $400 \mathrm{mg}$ (loading dose) or placebo ( $0.9 \%$ saline) subcutaneously at weeks 0,2 , and 4 . At Week 2 , all patients received intramuscular injections of 23 valent pneumococcal polysaccharide vaccine (Pneumovax 23, Merck \& Co. Inc.) and the 2009-2010 (Northern Hemisphere) H1N1,H3N2 B/Brisbane trivalent influenza virus vaccine (Afluria, Merck \& Co. Inc.). Blood samples were collected at Week 2 to assess baseline serum antibody titers for influenza and pneumococcal antigens and at Week 6 (i.e., 4 weeks after vaccination) for immune response evaluation; assessment of antibody titers was not undertaken at further timepoints.

Patients who completed the randomized controlled trial (RCT) were eligible to enter the optional OLE (NCT00993668). In the OLE, patients who received CZP during the RCT were administered CZP $200 \mathrm{mg}$ every other week (Q2W) from weeks 6 to 30 ; those who were previously randomized to placebo were given CZP $400 \mathrm{mg}$ (loading dose) at weeks 6, 8, and 10, followed by CZP $200 \mathrm{mg}$ Q2W from weeks 12 to 30 . We report vaccine responses from the RCT, and safety data from both the single-blind and OLE phases.

Patients. Patients were aged $\geq 18$ years with adult-onset RA as defined by the 1987 American College of Rheumatology criteria $^{36}$, of $\geq 6$ months' duration and active disease at baseline (defined as $\geq 4$ tender/painful joints and $\geq 4$ swollen joints; 28 -joint count). Patients must have discontinued anakinra and etanercept for $\geq 1$ month, rituximab for $\geq 6$ months, and any other biological DMARD for $\geq 3$ months prior to baseline. Patients were excluded from the study if they had received treatment with CZP at any previous time, had a recent $(<3$-month) pneumococcal or influenza infection, or had received a pneumococcal vaccine within 5 years or an influenza vaccine within 6 months. Patients were allowed to continue their pre-study nonbiologic therapies, including nonsteroidal antiinflammatory drugs, corticosteroids (prednisone equivalent $\leq 10 \mathrm{mg} /$ day), and DMARD (including MTX). Changes in DMARD dose regimens were not permitted within 1 month prior to baseline or during the study.

Antibody assays. Serum pneumococcal antibody titers were determined with a multiplexed indirect immunofluorescent assay using the Luminex platform (Millipore). Serum samples were pre-absorbed with pneumococcal cell wall polysaccharide mixture (CWPS multi). The 89SF pooled serum standard was used for the assay. Serum influenza antibody titers were determined using a hemagglutination inhibition antibody assay ${ }^{37,38}$. The influenza antibody analyses were run in triplicate, and the reporting was by geometric mean titer. All pneumococcal and influenza antibody samples were analyzed by Focus Diagnostics Inc. Antibody titer values were log-transformed.

Vaccine analyses. The primary objective of the study was to assess the humoral immune response to the trivalent influenza virus and the 23-valent pneumococcal vaccines in patients with RA receiving CZP versus placebo. The co-primary endpoints were the proportion of patients who achieved a satisfactory humoral immune response to each vaccine at Week 6 . Satisfactory humoral immune responses were defined as (1) $\geq 2$-fold titer increase postvaccination in $\geq 3$ of 6 pneumococcal antigens $(6 \mathrm{~B}, 9 \mathrm{~V}, 14$, $18 \mathrm{C}, 19 \mathrm{~F}$, and $23 \mathrm{~F}$; analysis similar to that previously undertaken for adalimumab ${ }^{18}$ ), and $(2) \geq 4$-fold increase postvaccination in $\geq 2$ of 3 influenza antigens [H1N1 (nonpandemic), H3N2, and B/Brisbane]. Vaccine response was assessed in patients with an absence of effective antibody titers at baseline (defined as $<1.6 \mu \mathrm{g} / \mathrm{ml}$ in $\geq 3$ of the 6 pneumococcal antigens and $<1: 40$ in $\geq 2$ of the 3 influenza antigens). According to these definitions, patients with pneumococcal antibody titer baseline values $<0.3 \mu \mathrm{g} / \mathrm{ml}$ had to reach $\geq 0.6 \mu \mathrm{g} / \mathrm{ml}$ (i.e., $\geq 2$-fold titer increase), while those with influenza antibody titer baseline values of $<1: 10$ needed to reach $\geq 1: 40$ (i.e., $\geq 4$-fold titer increase), to be classified as achieving a satisfactory response. Co-primary endpoints were assessed independently of each other (i.e., the percentage of patients who achieved the first endpoint may not have been the same as those who achieved the second endpoint). Thus, the results are presented separately.

Secondary endpoints were (1) proportion of all patients, including those

Personal non-commercial use only. The Journal of Rheumatology Copyright @ 2014 . All rights reserved. 


\section{A. Study Design}

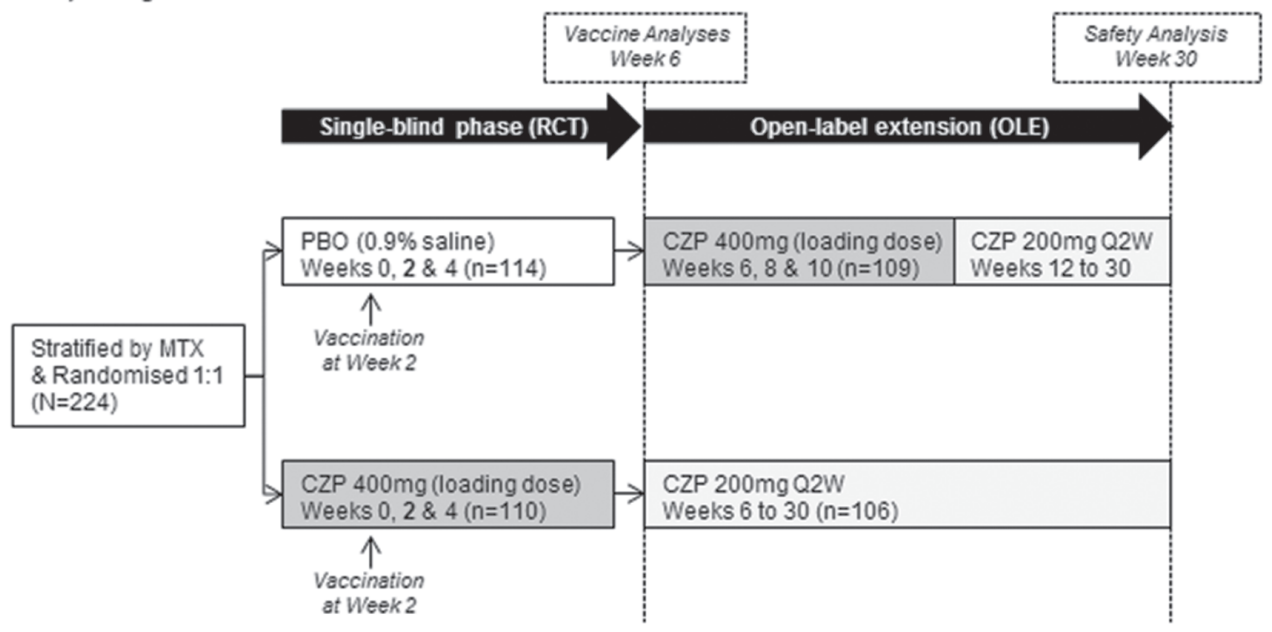

B. Patient Distribution

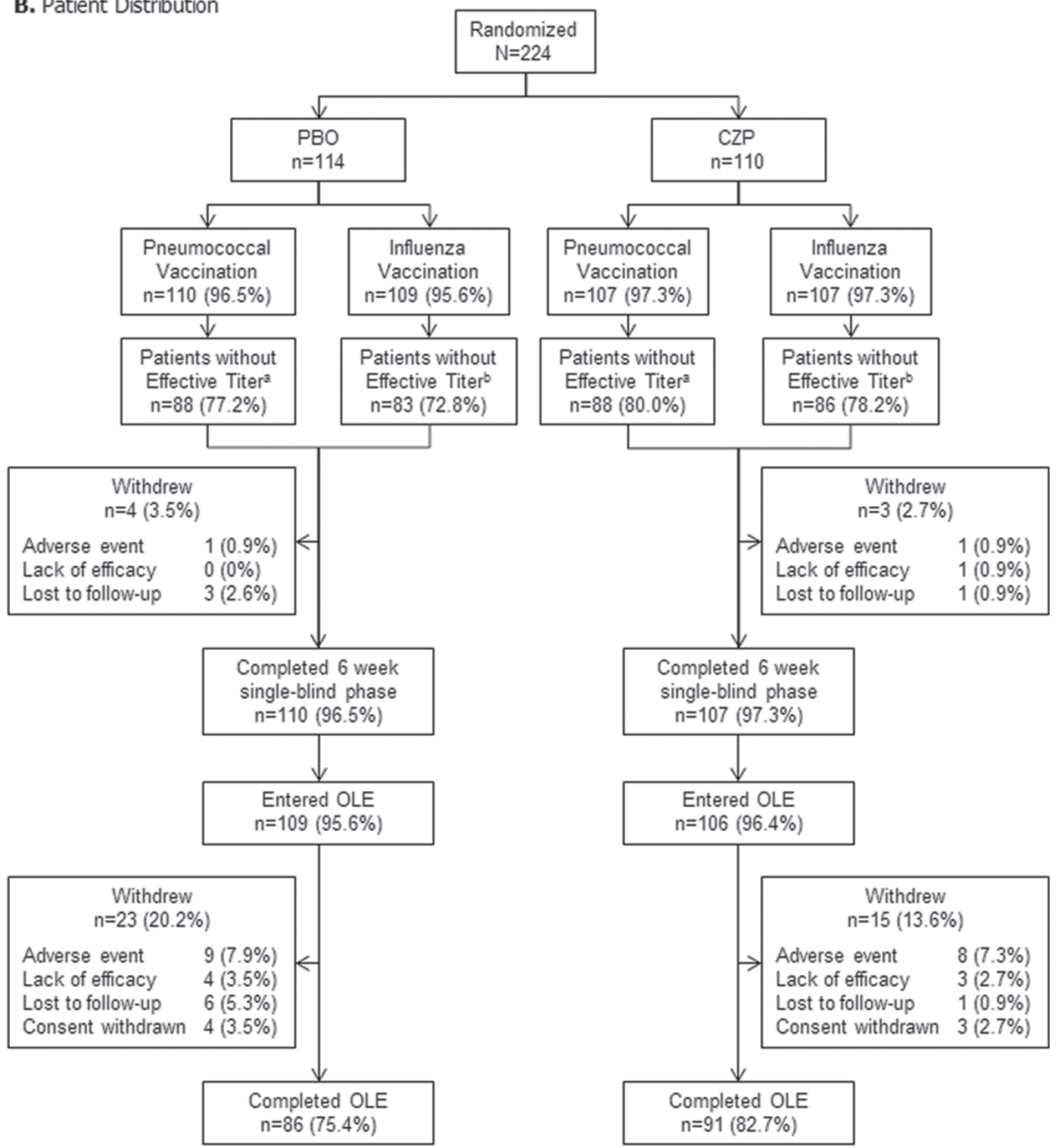

Figure 1. Study design and patient distribution.

${ }^{a}$ Absence of effective pneumococcal antibody titer at baseline (defined as $<1.6 \mu \mathrm{g} / \mathrm{ml}$ in $\geq 3$ of the pneumococcal antigens $6 \mathrm{~B}$, $9 \mathrm{~V}, 14,18 \mathrm{C}, 19 \mathrm{~F}$, and $23 \mathrm{~F}$ ). b Absence of effective influenza antibody titer at baseline [defined as $<1: 40$ in $\geq 2$ of the influenza antigens H1N1 (nonpandemic), $\mathrm{H} 3 \mathrm{~N} 2$, and B/Brisbane]. RCT: randomized controlled trial; PBO: placebo; MTX: methotrexate; CZP: certolizumab pegol; Q2W: dose every 2 weeks. 
with effective antibody titers at baseline, who achieved a satisfactory humoral immune response at Week 6; (2) mean change from baseline (increase) in antibody titers by individual antigen at Week 6; (3) proportion of patients who developed a satisfactory humoral immune response at Week 6; (4) proportion of patients who achieved a satisfactory humoral immune response at Week 6 by individual antigen; (5) proportion of patients who achieved a satisfactory humoral immune response to the pneumococcal and influenza vaccines at Week 6, stratified by MTX use at baseline; and (6) proportion of patients who achieved a satisfactory humoral immune response to the pneumococcal and influenza vaccines at Week 6 stratified by use of any DMARD (including MTX) or corticosteroids at baseline, C-reactive protein (CRP) levels of $<5 \mathrm{mg} / 1 \mathrm{or} \geq 5 \mathrm{mg} / 1$ at baseline, age ( $<65$ yrs or $\geq 65 \mathrm{yrs})$, and sex.

Statistical analyses. The primary endpoints were evaluated in patients without effective titers at baseline. The secondary endpoints were evaluated in both patients without effective titers at baseline, and also in all patients (including those who had effective titers at baseline). The difference between treatments was compared by examining the proportion of patients who achieved a satisfactory humoral immune response, as defined above for each endpoint. Each within-treatment estimate of proportion, and the difference in proportions between the treatment groups, were presented with a $95 \%$ CI constructed from an approximation to the normal distribution.

All analyses were based on observed data only. Only patients with serum antibody titer samples at Week 2 and Week 6 were analyzed; antibody titers were not analyzed at further timepoints. The ratio of geometric means for the changes from baseline between the treatment groups was calculated with an associated $95 \%$ CI by comparing log-transformed values to the normal distribution.

Adverse events and safety. The safety set consisted of all randomized patients who received at least 1 administration of either CZP or placebo. Safety assessments included monitoring and recording of adverse events (AE) at each visit during the RCT. The safety of CZP was also assessed during the 6-month OLE; the OLE safety dataset could include events experienced by patients originally randomized to placebo during the RCT who subsequently received CZP in the OLE.

\section{RESULTS}

Patients. A total of 224 patients were randomized, of which 217 (96.9\%) completed the 6-week single-blind phase/RCT (Figure 1B). Of the randomized patients, 217 (96.9\%) received the pneumococcal vaccine and 216 (96.4\%) received the influenza vaccine. Of these patients, 176 $(78.6 \%)$ of those who received the pneumococcal vaccine and $169(75.4 \%)$ of those who received the influenza vaccine did not have effective titers at baseline. Overall, 215 patients $(96.0 \%)$ entered the OLE: 109 (95.6\%) placebo and 106 (96.4\%) CZP patients. Of all patients randomized, 110 (96.5\%) placebo and 107 (97.3\%) CZP patients completed the RCT, with $86(75.4 \%)$ placebo and 91 (82.7\%) CZP patients completing the OLE.

Baseline demographics and disease characteristics were similar between the treatment groups (Table 1). Overall, 68.3\% of patients (placebo 68.4\%; CZP 68.2\%) received concomitant MTX (Table 1; mean dose $16.6 \mathrm{mg} /$ week).

Immune response to pneumococcal vaccine. In patients without effective titers at baseline, $62.5 \%$ of placebo and $54.5 \%$ of CZP patients achieved a satisfactory humoral immune response to pneumococcal vaccination at Week 6
Table 1. Patient demographics and disease characteristics (all randomized patients; $\mathrm{n}=224$ ).

\begin{tabular}{lcc}
\hline & PBO, $\mathrm{n}=114$ & $\mathrm{CZP}, \mathrm{n}=110$ \\
\hline Demographic & & \\
Age, yrs, mean (SD) & $52.7(11.1)$ & $53.1(11.8)$ \\
Sex, \% female & 76.3 & 83.6 \\
Disease characteristics & & \\
Duration, yrs, mean (SD) & $7.9(8.4)$ & $7.4(8.1)$ \\
Duration $>$ 2 yrs, $\mathrm{n}(\%)$ & $88(77.2)$ & $72(65.5)$ \\
TJC, mean (SD) & $16.0(7.1)$ & $15.7(7.6)$ \\
SJC, mean (SD) & $11.0(5.6)$ & $11.7(5.3)$ \\
DAS28-CRP, mean (SD) & $5.5(0.9)$ & $5.5(1.0)$ \\
CRP, mg/l, median (min, max) & $5.1(0.6,96.9)$ & $5.1(0.6,97.7)$ \\
CRP, $\leq 5$ mg/l, n (\%) & $56(49.1)$ & $54(49.1)$ \\
CRP, $>5$ mg/l, $(\%)$ & $58(50.9)$ & $56(50.9)$ \\
Concomitant therapy & & \\
Concomitant MTX use, $\mathrm{n}(\%)$ & $78(68.4)$ & $75(68.2)$ \\
Concomitant MTX dose, mg/week, & & \\
$\quad$ mean (SD) & $17.2(5.0)$ & $15.9(4.6)$ \\
Any concomitant DMARD, & & \\
$\quad$ including MTX, n (\%) & $91(79.8)$ & $92(83.6)$ \\
Corticosteroid use, n (\%) & $42(36.8)$ & $47(42.7)$ \\
\hline
\end{tabular}

${ }^{\mathrm{a}}$ Assessment based on 28 joints. ${ }^{\mathrm{b}} \mathrm{CRP}<5 \mathrm{mg} / \mathrm{l}$ is the central laboratory normal value. PBO: placebo; CZP: certolizumab pegol; CRP: C-reactive protein; DAS28: 28-joint disease activity score; DMARD: disease-modifying antirheumatic drug; MTX: methotrexate; SJC: swollen joint count; TJC: tender joint count.

(difference in proportions was -8.0 percentage points; $95 \%$ CI, -22.5 to $6.6 \%$; Figure 2). Similarly, in all patients, including those with effective titers at baseline, $58.2 \%$ of placebo and $53.3 \%$ of CZP patients achieved a satisfactory pneumococcal humoral immune response at Week 6 (difference in proportions was -4.9 percentage points; $95 \%$ CI, -18.1 to $8.3 \%$; Figure 2).

Evaluation of percent mean changes from baseline for antibody titers showed $\mathrm{a} \geq 2$-fold increase for each pneumococcal antigen in both treatment groups at Week 6 in patients without effective antibody titers at baseline, and also in all patients (including those with effective titers at baseline; Table 2). In all patients, $65.5 \%$ (95\% CI, 56.6 to $74.3 \%$ ) in the placebo group and $62.6 \%$ (95\% CI, 53.4 to $71.8 \%$ ) in the CZP group developed satisfactory antibody titers at Week 6. In patients without effective titers at baseline, the proportion of patients with satisfactory antibody titers at Week 6 was slightly lower in CZP patients (50.7\%; $95 \%$ CI, 39.4 to $62.0 \%$ ) compared with placebo (57.3\%; $95 \%$ CI, 46.1 to $68.5 \%)$.

The percentage of patients without effective titers at baseline who achieved a satisfactory humoral immune response for pneumococcal antigens $6 \mathrm{~B}, 14,19 \mathrm{~F}$, and $23 \mathrm{~F}$ at Week 6 was similar in the placebo and CZP groups (Table 2). Response rates varied depending on the specific antigen; however, the antibody response was broadly uniform with a similar range of response between placebo $(48.9 \%$ to

Personal non-commercial use only. The Journal of Rheumatology Copyright $\subset$ 2014. All rights reserved. 


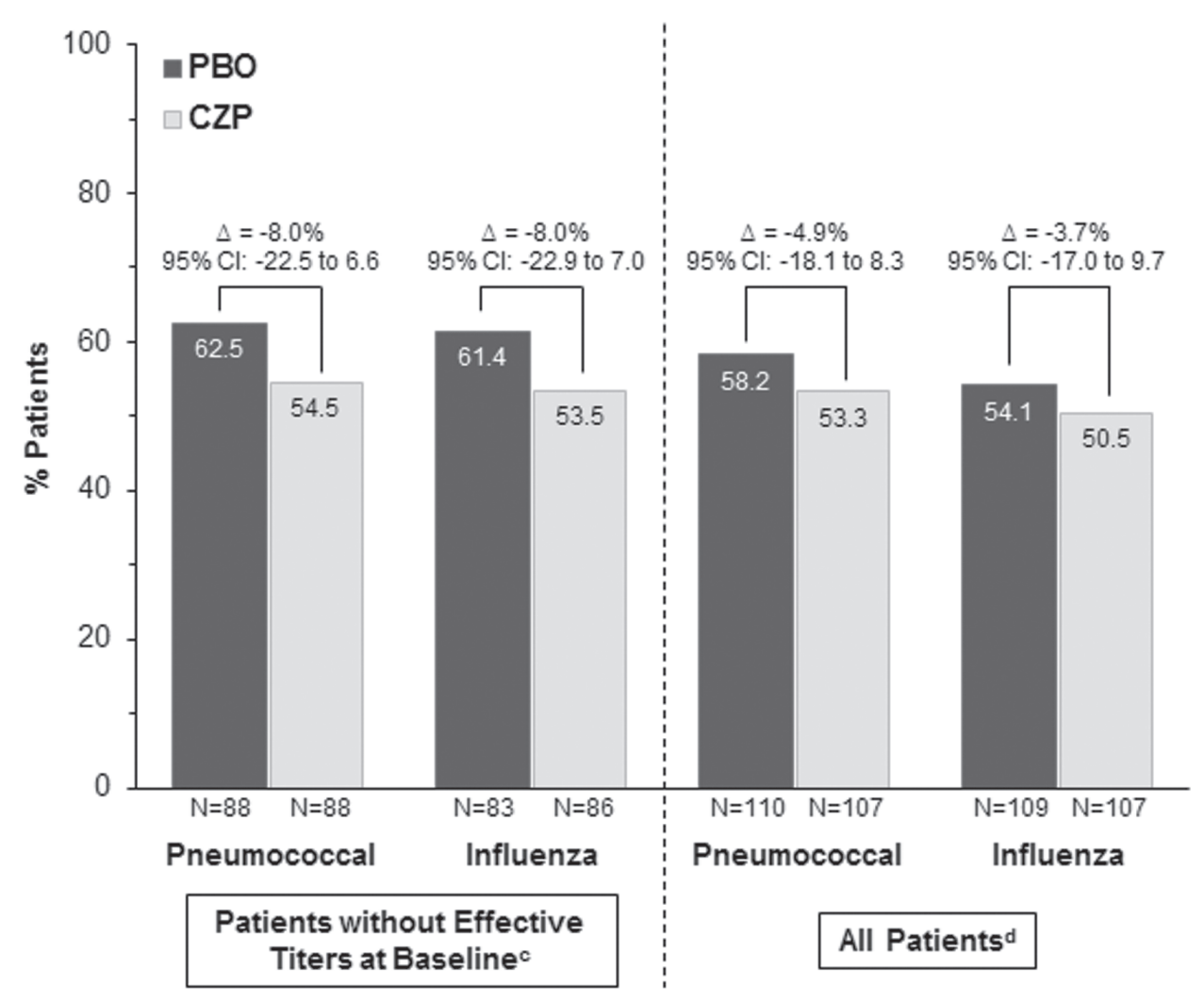

Figure 2. Proportion of patients who achieved a satisfactory humoral immune response $\mathrm{a}^{\mathrm{a}}$ at $\mathrm{Week}^{\mathrm{b}}$ to

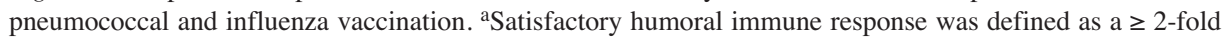
titer increase postvaccination in $\geq 3$ of 6 pneumococcal antigens $(6 \mathrm{~B}, 9 \mathrm{~V}, 14,18 \mathrm{C}, 19 \mathrm{~F}$, and $23 \mathrm{~F})$ and $\geq 4$-fold increase postvaccination for $\geq 2$ of 3 influenza antigens [H1N1 (nonpandemic), H3N2, and B/Brisbane]. ${ }^{\mathrm{b}}$ Four weeks postvaccination. ${ }^{\mathrm{c}}$ Absence of effective antibody titers at baseline were defined as $<1.6 \mu \mathrm{g} / \mathrm{ml}$ in $\geq 3$ of the 6 pneumococcal antigens assessed, and $<1: 40$ in $\geq 2$ of the 3 influenza antigens assessed. ${ }^{\mathrm{d}}$ All patients includes patients without effective titers at baseline. PBO: placebo; CZP: certolizumab pegol.

$65.9 \%$ ) and CZP (38.6\% to $65.9 \%$ ) groups (Table 2). Similar results were observed in all patients, which included those who had effective titers at baseline (Table 2).

The ability to mount a satisfactory response to pneumococcal vaccination was evaluated in patients without effective titers at baseline stratified by concomitant use of MTX, any DMARD (including MTX), or corticosteroids, and by age, sex, and baseline CRP levels. In general, the percentage of patients who developed a satisfactory response to pneumococcal antigens at Week 6 was numerically lower in the CZP group compared with the placebo group (Table 3). In patients without effective titers at baseline, both placebo and CZP patients who received concomitant MTX had lower vaccine responses compared with those who did not (CZP vs placebo: with concomitant MTX, $44.4 \%$ vs $50.0 \%$; without concomitant MTX, $80.0 \%$ vs $89.3 \%$; Table 3). Similarly, the response rates were reduced in placebo and CZP patients with concomitant use of any DMARD (including MTX; Table 3). The vaccine response was similar in both placebo and CZP patients with baseline CRP levels of $\leq 5 \mathrm{mg} / \mathrm{l}$ or $>5 \mathrm{mg} / \mathrm{l}$, and in those aged $<65$ years (Table 3 ). Response rates were lower in patients $\geq 65$ years treated with CZP versus placebo $(27.3 \%$ and $44.4 \%$, respectively), although the total patient number in this group was small (Table 3; number of patients $\geq 65$ years for each group varied between 9 and 12). Vaccine responses were also lower in females compared with males (Table 3).

Immune response to influenza vaccine. In patients without effective titers at baseline, $61.4 \%$ of placebo and $53.5 \%$ of CZP patients achieved a satisfactory humoral immune response to influenza vaccine at Week 6 (difference in proportions: -8.0 percentage points; $95 \% \mathrm{CI},-22.9$ to $7.0 \%$; Figure 2). Vaccine responses were similar in all patients (including those with effective titers at baseline), with $54.1 \%$ placebo and $50.5 \%$ CZP patients achieving a satisfactory humoral immune response at Week 6 (difference in proportions: -3.7 percentage points; $95 \% \mathrm{CI}-17.0$ to $9.7 \%$; Figure 2). Evaluation of percent mean changes from baseline for individual antibody titers in CZP-treated patients without effective titers at baseline showed there was a $>$ 4-fold increase for all antigens (Table 2). Meanwhile, analysis in all CZP-treated patients (including those with effective titers at baseline) showed a > 4-fold (400\%)

Personal non-commercial use only. The Journal of Rheumatology Copyright @ 2014 . All rights reserved. 
Table 2. Pneumococcal and influenza antigen antibody titer change from vaccine baseline (Week 2) to Week 6 and percentage of patients with a satisfactory humoral response to each antigen at Week 6.

\begin{tabular}{cccc}
\multicolumn{3}{c}{ Patients Without Effective Antibody Titers at Baseline } \\
n \\
Baseline Week 6 & $\%$ Change & $\%$ Pts \\
& Titer $^{\mathrm{a}} \quad$ Titer $^{\mathrm{c}, \mathrm{d}}$ & from & Satisfactory \\
& & Baseline & Humoral \\
& & $(95 \% \mathrm{CI})$ & Response $^{\mathrm{d}}$ \\
& & & $(95 \% \mathrm{CI})$
\end{tabular}

\begin{tabular}{|c|c|c|}
\hline $\begin{array}{c}\text { Baseline } \\
\text { Titer }^{\mathrm{c}}\end{array}$ & $\begin{array}{l}\text { Week } 6 \\
\text { Titer }{ }^{\mathrm{c}, \mathrm{d}}\end{array}$ & $\begin{array}{l}\text { \% Change } \\
\text { from } \\
\text { Baseline } e^{\mathrm{c}, \mathrm{d}} \\
(95 \% \mathrm{CI})\end{array}$ \\
\hline
\end{tabular}

$\%$ Pts

Satisfactory

Humoral

Response $^{\mathrm{d}}$

(95\% CI)

\begin{tabular}{|c|c|c|c|c|c|c|c|c|c|c|}
\hline \multicolumn{11}{|c|}{$\begin{array}{l}\text { Pneumococcal Antigen } \\
6 \mathrm{~B}\end{array}$} \\
\hline $\mathrm{PBO}$ & 88 & 0.4 & 1.2 & $319.4(241.2-423.0)$ & $48.9(38.4-59.3)$ & 110 & 0.5 & 1.5 & $287.6(222.6-371.6)$ & $45.5(36.1-54.8)$ \\
\hline $\mathrm{CZP}$ & 88 & 0.3 & 0.9 & $284.2(218.5-369.8)$ & $40.9(30.6-51.2)$ & 107 & 0.5 & 1.2 & $255.9(204.0-321.0)$ & $38.3(29.1-47.5)$ \\
\hline \multicolumn{11}{|l|}{$9 \mathrm{~V}$} \\
\hline $\mathrm{PBO}$ & 88 & 0.4 & 1.4 & $381.7(292.5-498.1)$ & $52.3(41.8-62.7)$ & 110 & 0.5 & 1.5 & $327.9(255.2-421.3)$ & $49.1(39.7-58.4)$ \\
\hline $\mathrm{CZP}$ & 88 & 0.3 & 1.0 & $374.3(299.2-468.3)$ & $56.8(46.5-67.2)$ & 107 & 0.3 & 1.2 & $352.5(288.6-430.5)$ & $57.0(47.6-66.4)$ \\
\hline \multicolumn{11}{|l|}{14} \\
\hline $\mathrm{PBO}$ & 88 & 1.0 & 5.1 & $515.7(378.1-703.3)$ & $65.9(56.0-75.8)$ & 110 & 1.4 & 6.1 & $448.3(342.7-586.4)$ & $61.8(52.7-70.9)$ \\
\hline $\mathrm{CZP}$ & 88 & 1.1 & 3.7 & $344.4(256.6-462.4)$ & $47.7(37.3-58.2)$ & 107 & 1.4 & 4.6 & $333.1(257.4-431.1)$ & $46.7(37.3-56.2)$ \\
\hline \multicolumn{11}{|l|}{$18 \mathrm{C}$} \\
\hline $\mathrm{PBO}$ & 88 & 0.6 & 2.4 & $415.7(310.7-556.2)$ & $56.8(46.5-67.2)$ & 110 & 0.8 & 2.9 & $361.0(274.9-474.0)$ & $53.6(44.3-63.0)$ \\
\hline $\mathrm{CZP}$ & 88 & 0.6 & 2.6 & $429.8(337.1-547.9)$ & $65.9(56.0-75.8)$ & 107 & 0.8 & 3.3 & $404.2(324.5-503.3)$ & $64.5(55.4-73.6)$ \\
\hline \multicolumn{11}{|l|}{$19 \mathrm{~F}$} \\
\hline $\mathrm{PBO}$ & 88 & 0.6 & 1.9 & $304.5(240.5-385.5)$ & $54.4(41.1-64.9)$ & 110 & 0.8 & 2.1 & $274.6(220.4-342.0)$ & $51.8(42.5-61.2)$ \\
\hline $\mathrm{CZP}$ & 88 & 0.6 & 1.6 & $271.8(215.9-342.3)$ & $44.3(33.9-54.7)$ & 107 & 0.7 & 1.9 & $260.3(212.3-319.0)$ & $43.9(34.5-53.3)$ \\
\hline \multicolumn{11}{|l|}{$23 \mathrm{~F}$} \\
\hline $\mathrm{PBO}$ & 88 & 0.4 & 1.3 & $305.0(241.0-385.9)$ & $51.1(40.7-61.6)$ & 110 & 0.5 & 1.5 & $281.4(225.9-350.4)$ & $48.2(38.8-57.5)$ \\
\hline $\mathrm{CZP}$ & 88 & 0.4 & 1.0 & $279.2(218.7-356.3)$ & $38.6(28.5-48.8)$ & 107 & 0.5 & 1.3 & $272.8(219.4-339.2)$ & $39.3(30.0-48.5)$ \\
\hline \multicolumn{11}{|c|}{ Influenza Antigen } \\
\hline \multicolumn{11}{|c|}{ H1N1 (nonpandemic) } \\
\hline $\mathrm{PBO}$ & 83 & 11.8 & 84.3 & $717.3(532.1-967.0)$ & $57.8(47.2-68.5)$ & 109 & 16.7 & 89.7 & $536.8(415.2-694.1)$ & $50.5(41.1-59.8)$ \\
\hline $\mathrm{CZP}$ & 86 & 11.3 & 50.9 & $449.7(344.5-587.1)$ & $50.0(39.4-60.6)$ & 107 & 16.6 & 65.7 & $397.0(313.0-503.7)$ & $45.8(36.4-55.2)$ \\
\hline \multicolumn{11}{|l|}{$\mathrm{H} 3 \mathrm{~N} 2$} \\
\hline $\mathrm{PBO}$ & 83 & 13.9 & 189.1 & $1361.0(982.8-1884.9)$ & $77.1(68.1-86.1)$ & 109 & 19.4 & 193.2 & $997.1(745.0-1334.7)$ & $70.6(62.1-79.2)$ \\
\hline $\mathrm{CZP}$ & 86 & 11.9 & 89.1 & $747.9(544.1-1027.9)$ & $59.3(48.9-69.7)$ & 107 & 16.4 & 105.0 & 641.5 (484.7-849.2) & $57.0(47.6-66.4)$ \\
\hline \multicolumn{11}{|c|}{ B/Brisbane } \\
\hline $\mathrm{PBO}$ & 83 & 9.2 & 46.0 & $498.7(382.3-650.5)$ & $48.2(37.4-58.9)$ & 109 & 11.0 & 46.1 & $419.1(333.4-526.8)$ & $44.0(34.7-53.4)$ \\
\hline $\mathrm{CZP}$ & 86 & 9.1 & 41.3 & $456.3(352.0-591.4)$ & $47.7(37.1-58.2)$ & 107 & 11.0 & 43.1 & $390.6(310.4-491.6)$ & $44.9(35.4-54.3)$ \\
\hline
\end{tabular}

a Absence of effective antibody titers at baseline were defined as $<1.6 \mu \mathrm{g} / \mathrm{ml}$ in $\geq 3$ of the 6 pneumococcal antigens assessed, and $<1: 40$ in $\geq 2$ of the 3 influenza antigens assessed. ${ }^{\mathrm{b}}$ All patients includes patients without effective titers at baseline. ${ }^{\mathrm{c}} \mathrm{Geometric}$ mean. ${ }^{\mathrm{d}} 4$ weeks postvaccination. PBO: placebo; CZP: certolizumab pegol; Pts: patients.

increase for H3N2 antigen and an almost 4-fold ( $\geq 390 \%)$ increase for $\mathrm{H} 1 \mathrm{~N} 1$ and $\mathrm{B} / \mathrm{Brisbane}$ antigens (Table 2). In the placebo group, there was a $>4$-fold increase from baseline in mean antibody titers for all antigens in patients without effective titers at baseline; a similar result was observed in all patients, which included those with effective titers at baseline (Table 2).

In patients without effective titers at baseline, $73.5 \%$ (CI 64.0 to $83.0 \%$ ) of placebo and $64.0 \%$ (CI 53.8 to $74.1 \%$ ) of CZP patients developed satisfactory influenza titers at Week 6. In all patients (which included those with effective titers at baseline), more than $70 \%$ developed satisfactory influenza antibody titers at Week 6 in both placebo (77.1\%; CI, 69.2 to $85.0 \%)$ and CZP (71.0\%; CI, 62.4 to $79.6 \%$ ) groups. When considering each antigen individually, the percentage of patients without effective titers at baseline who achieved a satisfactory humoral immune response to the $\mathrm{H} 1 \mathrm{~N} 1$ and $\mathrm{B} /$ Brisbane antigens was similar in the placebo and CZP groups at Week 6 (Table 2). In contrast, the immune response to the $\mathrm{H} 3 \mathrm{~N} 2$ antigen was lower in the CZP group compared with the placebo group $(59.3 \%$ vs $77.1 \%$, respectively). Results were similar in all patients, which included those with effective titers at baseline (Table 2).

In general, the proportion of patients without effective titers at baseline who achieved a satisfactory humoral immune response to influenza antigens at Week 6 was lower in the CZP group compared with placebo for most stratification subgroups [concomitant MTX, any DMARD (including MTX), corticosteroids, age, and sex; Table 3]. The vaccine response was lower in both placebo and CZP patients who received concomitant MTX compared with those who did not (CZP vs placebo: with concomitant MTX, $45.8 \%$ vs $50.9 \%$; without concomitant MTX, $70.4 \%$ vs $84.6 \%$ ). Similarly, the response rates were reduced in 
Table 3. Satisfactory humoral immune response to pneumococcal and influenza vaccines at Week $6^{\text {a }}$ by stratification subgroups in patients without effective antibody titers at baseline ${ }^{\mathrm{b}}$.

\begin{tabular}{|c|c|c|c|c|}
\hline \multirow[b]{2}{*}{ Treatment } & \multicolumn{2}{|c|}{ Pneumococcal Response } & \multicolumn{2}{|c|}{ Influenza Response } \\
\hline & $\mathrm{PBO}$ n/N (\%) (95\% CI) & $\mathrm{CZP}$ n/N (\%) (95\% CI) & $\mathrm{PBO}$ n/N (\%) (95\% CI) & $\mathrm{CZP} \mathrm{n} / \mathrm{N}(\%)(95 \% \mathrm{CI})$ \\
\hline \multicolumn{5}{|c|}{ Concomitant MTX use } \\
\hline No & $25 / 28(89.3)(77.8-100.0)$ & 20/25 (80.0) (64.3-95.7) & $22 / 26(84.6)(70.7-98.5)$ & $19 / 27(70.4)(53.1-87.6)$ \\
\hline \multicolumn{5}{|c|}{ Any DMARD use (including MTX) } \\
\hline Yes & $39 / 70(55.7)(44.1-67.4)$ & $37 / 74(50.0)(38.6-61.4)$ & $37 / 66(56.1)(44.1-68.0)$ & $35 / 71(49.3)(37.7-60.9)$ \\
\hline \multicolumn{5}{|c|}{ Corticosteroid use } \\
\hline Yes & $22 / 33(66.7)(50.6-82.8)$ & $23 / 38(60.5)(45.0-76.1)$ & $17 / 29(58.6)(40.7-76.5)$ & $18 / 38(47.4)(31.5-63.2)$ \\
\hline No & $33 / 55(60.0)(47.1-72.9)$ & $25 / 50(50.0)(36.1-63.9)$ & $34 / 54(63.0)(50.1-75.8)$ & $28 / 48(58.3)(44.4-72.3)$ \\
\hline \multicolumn{5}{|l|}{ CRP level } \\
\hline$\leq 5 \mathrm{mg} / \mathrm{l}^{\mathrm{c}}$ & $24 / 44(54.5)(39.8-69.3)$ & $24 / 40(60.0)(44.8-75.2)$ & $26 / 41(63.4)(48.7-78.2)$ & $21 / 42(50.0)(34.9-65.1)$ \\
\hline$>5 \mathrm{mg} / \mathrm{l}$ & $31 / 44(70.5)(57.0-83.9)$ & $24 / 48(50.0)(35.9-64.1)$ & $25 / 42(59.5)(44.7-74.4)$ & $25 / 44(56.8)(42.2-71.5)$ \\
\hline \multicolumn{5}{|l|}{ Age } \\
\hline Female & $39 / 64(60.9)(49.0-72.9)$ & $39 / 73(53.4)(42.0-64.9)$ & $37 / 65(56.9)(44.9-69.0)$ & $36 / 72(50.0)(38.5-61.5)$ \\
\hline
\end{tabular}

${ }^{a}$ Four weeks postvaccination. ${ }^{\mathrm{b}}$ Absence of effective antibody titers at baseline was defined as $<1.6 \mu \mathrm{g} / \mathrm{ml}$ in $\geq 3$ of the 6 pneumococcal antigens assessed, and $<1: 40$ in $\geq 2$ of the 3 influenza antigens assessed. ${ }^{\mathrm{c}} \mathrm{CRP}<5 \mathrm{mg} / \mathrm{l}$ is the central laboratory normal value. CRP: C-reactive protein; PBO: placebo; CZP: certolizumab pegol; DMARD: disease-modifying antirheumatic drug; MTX: methotrexate.

placebo and CZP patients with concomitant use of any DMARD (including MTX; Table 3). The vaccine response was similar in CZP patients with baseline CRP levels of $\leq 5$ $\mathrm{mg} / \mathrm{l}$ or $>5 \mathrm{mg} / \mathrm{l}$, and those who were aged $<65$ years; results were comparable in the placebo group (Table 3). The response rate was lower in CZP patients $\geq 65$ years compared with CZP patients $<65$ years, but a meaningful comparison is limited by the much lower number of patients in the $\geq 65$-year-old group. Vaccine responses were lower in females compared with males (Table 3).

Adverse events and safety. Overall, no notable differences were observed in the incidence of $\mathrm{AE}$ between placebo and CZP groups during the RCT (62.3\% vs $63.6 \%$, respectively; Table 4). The majority of $\mathrm{AE}$ in both groups were mild (36.8\% placebo vs $40.0 \% \mathrm{CZP}$ ) or moderate (21.9\% placebo vs $20.9 \%$ CZP) in intensity. The most frequent AE reported during the RCT were nasopharyngitis and headaches, which occurred in $5.3 \%$ of placebo and $9.1 \%$ of CZP patients and $13.2 \%$ of placebo and $7.3 \%$ of CZP patients, respectively (Table 4). Nasopharyngitis and upper respiratory tract infection were the most frequently reported $\mathrm{AE}$ in all CZP patients, including those treated during both the RCT and OLE, and occurred in $14.2 \%$ and $13.7 \%$ of these patients, respectively. AE considered by the investigator as possibly drug-related were similar between placebo and CZP groups during the RCT (21.9\% vs $24.5 \%$, respectively; Table 4$)$.

Injection site pain, associated with randomized treatment (i.e., not vaccination) was reported in $3.5 \%$ of patients in the placebo group, in no patients in the RCT CZP group, and in
$4.1 \%$ of CZP-treated patients overall (RCT and OLE, including placebo patients that entered the OLE). Injection site reaction associated with randomized treatment, besides pain, occurred in no patients in the placebo group, $4.5 \%$ of RCT CZP patients, and in $4.6 \%$ of CZP-treated patients overall. Upper respiratory tract infections occurred in 6 patients $(5.3 \%)$ in the placebo group and 4 patients $(3.6 \%)$ in the CZP group.

During the RCT, serious AE occurred in 1 patient $(0.9 \%)$ in the placebo group (chordoma that led to study withdrawal) and in 2 patients (1.8\%) in the CZP group (1 case of fatal bladder cancer diagnosed 14 days after initial CZP dose, with previous history of hematuria, that led to study withdrawal and 1 case of new transient ischemic attack and carotid artery stenosis, considered unrelated by the investigator). Serious AE occurred in $6.8 \%$ of CZP-treated patients overall (combined RCT and OLE). There were no cases reported in the category of tuberculosis (TB) in either group during the RCT, although 2 cases $(0.9 \%)$ were reported during the OLE after CZP treatment. One CZP-treated patient (who had a negative purified protein derivative skin TB test at screening) developed a positive TB test (latent TB at Day 50). The patient was a hospital worker who was exposed to a patient with $\mathrm{TB}$ during the study, after which they tested positive for TB by means of a QuantiFERON-TB-Gold test; the patient was treated with isoniazid and discontinued from CZP treatment on Day 71. The event was considered unrelated to the study drug by the investigator and was resolving after treatment.

Personal non-commercial use only. The Journal of Rheumatology Copyright @ 2014 . All rights reserved. 
Table 4. Treatment-emergent AE up to Week $6^{\mathrm{a}}$ (safety population) of the RCT and for all patients treated with CZP in both the RCT and OLE periods.

\begin{tabular}{|c|c|c|c|}
\hline & $\mathrm{PBO}, \mathrm{n}=114$ & $\mathrm{CZP}, \mathrm{n}=110$ & $\begin{array}{c}\text { All CZP RCT }+ \text { OLE }^{b} \\
\text { n }=219\end{array}$ \\
\hline Duration of exposure, days, mean (SD) & $43.0(4.9)$ & $43.2(5.5)$ & $190^{\mathrm{c}}$ \\
\hline Any AE, n $(\%$ d $)$ & $71(62.3)$ & $70(63.6)$ & $202(92.2)$ \\
\hline \multicolumn{4}{|l|}{ Any $\mathrm{AE}$ by maximum intensity, $\mathrm{n}\left(\%^{\mathrm{d}}\right)$} \\
\hline Mild & $42(36.8)$ & $44(40.0)$ & $76(34.7)$ \\
\hline Moderate & $25(21.9)$ & $23(20.9)$ & $102(46.6)$ \\
\hline Severe & $4(3.5)$ & $3(2.7)$ & $24(11.0)$ \\
\hline Drug-related $\mathrm{AE}^{\mathrm{e}}, \mathrm{n}\left(\%^{\mathrm{d}}\right)$ & $25(21.9)$ & $27(24.5)$ & $101(46.1)$ \\
\hline \multicolumn{4}{|l|}{ Most frequent $\mathrm{AE}^{\mathrm{f}}$} \\
\hline Nasopharyngitis & $6(5.3)$ & $10(9.1)$ & $31(14.2)$ \\
\hline Headache & $15(13.2)$ & $8(7.3)$ & $28(12.8)$ \\
\hline Discontinuations due to AE, $\mathrm{n}\left(\%^{\mathrm{d}}\right)$ & $1(0.9)$ & $3(2.7)$ & $18(8.2)$ \\
\hline Serious AE, $\mathrm{n}\left(\%^{\mathrm{d}}\right)$ & $1(0.9)$ & $2(1.8)$ & $15(6.8)$ \\
\hline Serious infections and infestations, $\mathrm{n}\left(\%^{\mathrm{d}}\right)$ & 0 & 0 & $8(3.7)$ \\
\hline Tuberculosis & 0 & 0 & $2(0.9)$ \\
\hline No. deaths, $\mathrm{n}\left(\%^{\mathrm{d}}\right)$ & 0 & $1(0.9)$ & $1(0.5)$ \\
\hline
\end{tabular}

\footnotetext{
${ }^{a}$ Four weeks postvaccination. ${ }^{\mathrm{b}}$ The data from the OLE phase includes events experienced by PBO patients who entered the OLE phase. ${ }^{c}$ Median exposure to CZP throughout SB and OLE periods. ${ }^{d}$ Percent of patients in group. ${ }^{\mathrm{e}} \mathrm{AE}$ considered related or possibly related to study drug by the investigator. ${ }^{\mathrm{f}} \mathrm{AE}$ occurring in $\geq 5 \%$ of patients in CZP group. AE: adverse event; RCT: randomized controlled trial; CZP: certolizumab pegol; SB: single-blind phase; OLE: open-label period; PBO: placebo.
}

Another CZP-treated patient had a history of latent TB and was treated for 4 months with isoniazid before inclusion into the trial. This patient had a negative baseline QuantiFERON-TB-Gold TB test and normal chest radiograph, but developed suspected pulmonary $\mathrm{TB}$ and pulmonary granuloma at Day 200 of the study based on chest radiograph. The case was resolving by the end of the study, after hospitalization and treatment for TB, and the event was considered related to study drug by the investigator.

As mentioned, 1 patient developed a fatal bladder cancer diagnosed 14 days after starting CZP treatment, the single death in the CZP group. This event was considered unrelated to the study drug. There were no deaths reported in the placebo group.

\section{DISCUSSION}

These data demonstrate that humoral immune responses to pneumococcal and influenza vaccines are maintained in patients with RA receiving treatment with CZP. At 4 weeks after vaccination, most patients $(60 \%$ to $80 \%)$ in both treatment groups developed satisfactory pneumococcal and influenza antibody titers. Further, results were similar in all patients, which included those with previous effective antibody titers, and in the subset of patients without previous effective titers.

Discordant immune response to vaccination has been reported in patients with RA treated with some TNF inhibitors and concomitant DMARD. In our study, humoral immune responses to pneumococcal and influenza vaccines were lower in CZP and placebo patients who received concomitant
MTX compared with those who did not. These results are expected, given that $68 \%$ of patients in the study had concomitant use of MTX at baseline, and are consistent with previous studies with other TNF inhibitors, which reported reduced response rates to influenza and pneumococcal vaccines in RA patients with concomitant MTX use ${ }^{18,20}$.

Concomitant use of corticosteroids or baseline CRP level did not affect the humoral immune response to pneumococcal and influenza vaccination in either treatment group. Other studies have reported similar results, with no association between influenza vaccine response and use of immunosuppressants/steroids in patients with $\mathrm{RA}^{39}$, and between pneumococcal vaccine response and measures of disease activity ${ }^{40}$. In line with other studies, the differences in responses observed in subgroups based on variables such as age and sex were not considered clinically relevant ${ }^{41}$. Alternatively, too few patients may be present in these patient subgroups to draw meaningful conclusions.

Previous analyses of pneumococcal vaccine response in healthy subjects have shown variability in humoral immune response to individual antigens, where not all patients responded to all antigens with $\mathrm{a} \geq 2$-fold increase in antibody titers ${ }^{42}$. Results in our study showed some variability in response to different pneumococcal antigens among patients with RA treated with CZP or placebo. However, $\mathrm{a} \geq 2$-fold increase in response to each of the 6 pneumococcal antigens was observed in about $40 \%$ to $60 \%$ of patients in both treatment groups, suggesting that patients with RA are able to develop an effective humoral immune response at 4 weeks after vaccination. 
Good humoral immune response to the influenza vaccine has been reported previously in patients with RA, although the responses were lower than in healthy controls ${ }^{43}$. In our study, the majority of patients without effective titers at baseline achieved a satisfactory humoral immune response to the influenza vaccine, with no apparent differences between the 2 treatments. In addition, there was a $\geq 4$-fold increase in antigen titers for each of the 3 influenza antigens in both treatment groups 4 weeks after vaccination, with a slightly less than 4-fold increase for the $\mathrm{B} /$ Brisbane and H1N1 antigens in the CZP treatment group, in all patients (including those with effective titers at baseline).

The safety profile of CZP in our study was consistent with that seen in previous trials ${ }^{26,27,28,31,33,44,45}$, with a low incidence of discontinuations due to $\mathrm{AE}$. The incidence of $\mathrm{AE}$ and serious $\mathrm{AE}$ was comparable in $\mathrm{CZP}$ and placebo groups, with no new safety signals detected during the 7.5-month followup of our study (RCT plus OLE). The incidence of injection site pain and injection site reactions was low in the CZP group (no patients and $4.5 \%$ patients, respectively, in the RCT) and comparable with placebo (3.5\% and no patients, respectively, in the RCT). This is similar to the previously reported range of $2-3 \%$ for injection site pain and $0.8-1.3 \%$ for injection site reaction in the RAPID 1 CZP group ${ }^{27}$.

Patients with RA developed effective antibody responses to pneumococcal and influenza vaccines, with comparable responses between CZP and placebo groups, 4 weeks after vaccination. These findings indicate that patients with RA receiving CZP treatment, including those concurrently receiving the loading dose, can mount an appropriate response to pneumococcal and influenza vaccines.

\section{ACKNOWLEDGMENT}

The authors thank the patients and investigators who participated in the study, and Niti Goel, MD, for scientific advice. The authors acknowledge Elizabeth Smith, UCB Pharma, Smyrna, USA, for publication management and Costello Medical Consulting for editorial and administrative support. Editorial services were also provided by Jaya Kolipaka from PAREXEL.

\section{REFERENCES}

1. Baum J. Infection in rheumatoid arthritis. Arthritis Rheum 1971;14:135-7.

2. Doran MF, Crowson CS, Pond GR, O'Fallon WM, Gabriel SE. Frequency of infection in patients with rheumatoid arthritis compared with controls: a population-based study. Arthritis Rheum 2002;46:2287-93.

3. Keystone EC. Does anti-tumor necrosis factor-alpha therapy affect risk of serious infection and cancer in patients with rheumatoid arthritis?: a review of longterm data. J Rheumatol 2011;38:1552-62.

4. Saag KG, Koehnke R, Caldwell JR, Brasington R, Burmeister LF, Zimmerman B, et al. Low dose long-term corticosteroid therapy in rheumatoid arthritis: an analysis of serious adverse events. Am J Med 1994;96:115-23.

5. Segal BH, Sneller MC. Infectious complications of immunosuppressive therapy in patients with rheumatic diseases. Rheum Dis Clin North Am 1997;23:219-37.

6. Rosenblum H, Amital H. Anti-TNF therapy: safety aspects of taking the risk. Autoimmun Rev 2011;10:563-8.

7. Ding T, Ledingham J, Luqmani R, Westlake S, Hyrich K, Lunt M, et al. BSR and BHPR rheumatoid arthritis guidelines on safety of anti-TNF therapies. Rheumatology 2010;49:2217-9.

8. Prevention CfDCa. General recommendations on immunization: recommendations of the Advisory Committee on Immunization Practices (ACIP). MMWR Morb Mortal Wkly Rep 2011;60:1-60.

9. Janssen Biotech Inc. Remicade prescribing information. Revised October 2011. [Internet. Accessed January 27, 2014.] Available from: www.remicade.com/shared/product/remicade/ prescribing-information.pdf

10. Abbott Laboratories. Humira prescribing information. Revised February 2013. [Internet. Accessed January 27, 2014.] Available from: http://www.rxabbvie.com/pdf/humira.pdf

11. UCB Pharma. Cimzia prescribing information. Revised November 2012. [Internet. Accessed January 27, 2014.] Available from: www.cimzia.com/pdf/MedicationGuide.pdf

12. Janssen Biotech Inc. Simponi (Golimumab) prescribing information. Revised May 2013. [Internet. Accessed January 27, 2014.] Available from: https://www.simponi.com/ prescribing-information.pdf

13. Amgen Inc., Pfizer Inc. Enbrel (etanercept) prescribing information. Revised December 2012. [Internet. Accessed January 27, 2014.] Available from: http://pi.amgen.com/united_states/ enbrel/derm/enbrel_pi.pdf

14. Desai SP, Turchin A, Szent-Gyorgyi LE, Weinblatt M, Coblyn J, Solomon DH, et al. Routinely measuring and reporting pneumococcal vaccination among immunosuppressed rheumatology outpatients: the first step in improving quality. Rheumatology 2011;50:366-72.

15. Gluck T, Muller-Ladner U. Vaccination in patients with chronic rheumatic or autoimmune diseases. Clin Infect Dis 2008; 46:1459-65.

16. Rahier JF, Moutschen M, Van Gompel A, Van Ranst M, Louis E, Segaert $\mathrm{S}$, et al. Vaccinations in patients with immune-mediated inflammatory diseases. Rheumatology 2010;49:1815-27.

17. Gelinck LB, van der Bijl AE, Beyer WE, Visser LG, Huizinga TW, van Hogezand RA, et al. The effect of anti-tumour necrosis factor alpha treatment on the antibody response to influenza vaccination. Ann Rheum Dis 2008;67:713-6.

18. Kaine JL, Kivitz AJ, Birbara C, Luo AY. Immune responses following administration of influenza and pneumococcal vaccines to patients with rheumatoid arthritis receiving adalimumab. J Rheumatol 2007;34:272-9.

19. Elkayam O, Caspi D, Reitblatt T, Charboneau D, Rubins JB. The effect of tumor necrosis factor blockade on the response to pneumococcal vaccination in patients with rheumatoid arthritis and ankylosing spondylitis. Semin Arthritis Rheum 2004;33:283-8.

20. Kapetanovic MC, Saxne T, Sjoholm A, Truedsson L, Jonsson G, Geborek P. Influence of methotrexate, TNF blockers and prednisolone on antibody responses to pneumococcal polysaccharide vaccine in patients with rheumatoid arthritis. Rheumatology 2006;45:106-11.

21. Visvanathan S, Keenan GF, Baker DG, Levinson AI, Wagner CL. Response to pneumococcal vaccine in patients with early rheumatoid arthritis receiving infliximab plus methotrexate or methotrexate alone. J Rheumatol 2007;34:952-7.

22. Bingham CO 3rd, Looney RJ, Deodhar A, Halsey N, Greenwald M, Codding $\mathrm{C}$, et al. Immunization responses in rheumatoid arthritis patients treated with rituximab: results from a controlled clinical trial. Arthritis Rheum 2010;62:64-74.

23. Tay L, Leon F, Vratsanos G, Raymond R, Corbo M. Vaccination response to tetanus toxoid and 23 -valent pneumococcal vaccines following administration of a single dose of abatacept: a randomized, open-label, parallel group study in healthy subjects. 
Arthritis Res Ther 2007;9:R38.

24. van Assen S, Holvast A, Benne CA, Posthumus MD, van Leeuwen MA, Voskuyl AE, et al. Humoral responses after influenza vaccination are severely reduced in patients with rheumatoid arthritis treated with rituximab. Arthritis Rheum 2010;62:75-81.

25. Thomas C, Moridani M. Interindividual variations in the efficacy and toxicity of vaccines. Toxicology 2010;278:204-10.

26. Fleischmann R, Vencovsky J, van Vollenhoven RF, Borenstein D, Box J, Coteur G, et al. Efficacy and safety of certolizumab pegol monotherapy every 4 weeks in patients with rheumatoid arthritis failing previous disease-modifying antirheumatic therapy: the FAST4WARD study. Ann Rheum Dis 2009;68:805-11.

27. Keystone E, Heijde DV, Mason D Jr., Landewe R, Vollenhoven RV, Combe B, et al. Certolizumab pegol plus methotrexate is significantly more effective than placebo plus methotrexate in active rheumatoid arthritis: findings of a fifty-two-week, phase III, multicenter, randomized, double-blind, placebo-controlled, parallel-group study. Arthritis Rheum 2008;58:3319-29.

28. Smolen J, Landewe RB, Mease P, Brzezicki J, Mason D, Luijtens $\mathrm{K}$, et al. Efficacy and safety of certolizumab pegol plus methotrexate in active rheumatoid arthritis: the RAPID 2 study. A randomised controlled trial. Ann Rheum Dis 2009;68:797-804.

29. Fleischmann R, Van Vollenhoven R, Vencovsky J, Alten R, Davies $\mathrm{O}$, Stach C, et al. Long-term safety and efficacy of 4-weekly certolizumab pegol in combination with methotrexate and as monotherapy in rheumatoid arthritis: 5 year results from an open label extension study. Arthritis Rheum 2012;64 Suppl 10:S565.

30. Keystone EC, Combe B, Smolen J, Strand V, Goel N, van Vollenhoven R, et al. Sustained efficacy of certolizumab pegol added to methotrexate in the treatment of rheumatoid arthritis: 2-year results from the RAPID 1 trial. Rheumatology 2012;51:1628-38.

31. Landewé R, Braun J, Deodhar A, Dougados M, Maksymowych WP, Mease PJ, et al. Efficacy of certolizumab pegol on signs and symptoms of axial spondyloarthritis including ankylosing spondylitis: 24-week results of a double-blind randomised placebo-controlled Phase 3 study. Ann Rheum Dis 2013;73:39-47.

32. Lichtenstein GR, Thomsen OO, Schreiber S, Lawrance IC, Hanauer $\mathrm{SB}$, Bloomfield R, et al. Continuous therapy with certolizumab pegol maintains remission of patients with Crohn's disease for up to 18 months. Clin Gastroenterol Hepatol 2010;8:600-9.

33. Mease PJ, Fleischmann R, Deodhar AA, Wollenhaupt J, Khraishi $\mathrm{M}$, Kielar D, et al. Effect of certolizumab pegol on signs and symptoms in patients with psoriatic arthritis: 24 -week results of a Phase 3 double-blind randomised placebo-controlled study (RAPID-PsA). Ann Rheum Dis 2013;73:48-55.

34. Reich K, Ortonne JP, Gottlieb AB, Terpstra IJ, Coteur G, Tasset C, et al. Successful treatment of moderate to severe plaque psoriasis with the PEGylated Fab' certolizumab pegol: results of a phase II randomized, placebo-controlled trial with a re-treatment extension. Br J Dermatol 2012;167:180-90.
35. Schreiber S, Khaliq-Kareemi M, Lawrance IC, Thomsen OO, Hanauer SB, McColm J, et al. Maintenance therapy with certolizumab pegol for Crohn's disease. N Engl J Med 2007;357:239-50.

36. Arnett FC, Edworthy SM, Bloch DA, McShane DJ, Fries JF, Cooper NS, et al. The American Rheumatism Association 1987 revised criteria for the classification of rheumatoid arthritis. Arthritis Rheum 1988;31:315-24.

37. Greenberg ME, Lai MH, Hartel GF, Wichems CH, Gittleson C, Bennet J, et al. Response to a monovalent 2009 influenza A (H1N1) vaccine. N Engl J Med 2009;361:2405-13.

38. Hemagglutination inhibition (HAI) test for titrating influenza virus A and B specific antibodies - Turkey RBCs. Cypress, California, USA: Focus Diagnostics Inc.; 2011.

39. Chalmers A, Scheifele D, Patterson C, Williams D, Weber J, Shuckett R, et al. Immunization of patients with rheumatoid arthritis against influenza: a study of vaccine safety and immunogenicity. J Rheumatol 1994;21:1203-6.

40. Elkayam O, Paran D, Caspi D, Litinsky I, Yaron M, Charboneau D, et al. Immunogenicity and safety of pneumococcal vaccination in patients with rheumatoid arthritis or systemic lupus erythematosus. Clin Infect Dis 2002;34:147-53.

41. Elkayam O, Bashkin A, Mandelboim M, Litinsky I, Comaheshter D, Levartovsky D, et al. The effect of infliximab and timing of vaccination on the humoral response to influenza vaccination in patients with rheumatoid arthritis and ankylosing spondylitis. Semin Arthritis Rheum 2010;39:442-7.

42. Go ES, Ballas ZK. Anti-pneumococcal antibody response in normal subjects: a meta-analysis. J Allergy Clin Immunol 1996;98:205-15.

43. Fomin I, Caspi D, Levy V, Varsano N, Shalev Y, Paran D, et al. Vaccination against influenza in rheumatoid arthritis: the effect of disease modifying drugs, including TNF alpha blockers. Ann Rheum Dis 2006;65:191-4.

44. van der Heijde D, Fleischmann R, Wollenhaupt J, Deodhar A, Kielar D, Woltering F, et al. Effect of different imputation approaches on the evaluation of radiographic progression in patients with psoriatic arthritis: results of the RAPID-PsA 24-week phase III double-blind randomised placebo-controlled study of certolizumab pegol. Ann Rheum Dis 2013;73:233-7.

45. van der Heijde D, Maksymowych W, Landewe R, Stach C, Hoepken B, Fichtner A, et al. Effect of certolizumab pegol on inflammation of spine and sacroiliac joints in patients with axial spondyloarthritis: 12 week magnetic resonance imaging results of a phase 3 double blind randomized placebo-controlled study [abstract]. Arthritis Rheum 2012;64 Suppl:S730. 